\title{
Intensity and spatial extension of drought in South Africa at different time scales
}

\author{
Mathieu Rouault ${ }^{1 *}$ and Yves Richard ${ }^{2}$ \\ ${ }^{1}$ Oceanography Department, University of Cape Town, Private Bag, Rondebosch 7701, South Africa \\ ${ }^{2}$ Centre de Recherches de Climatologie, UMR 5080, CNRS/Université de Bourgogne, France
}

\begin{abstract}
The standardised precipitation index (SPI) is an index that allows monitoring the intensity and spatial extension of droughts at different time scales $(3,6,12$ and 24 months). The SPI is linked to the probability occurrence of dry or wet events. The SPI allows monitoring operationally any location with a 30-year time series. It is also used here to do a retrospective analysis of the spatial extension and intensity of droughts in South Africa since 1921. According to this index, the 8 most severe droughts at the 6-month time scale for the summer rainfall region of South Africa happened in 1926, 1933, 1945, $1949,1952,1970,1983$ and 1992. There is considerable decadal variability and an 18 to 20 year cycle is only found in the number of dry districts. The total number of wet and dry districts per decade seems to have increased since the 1960s. Drought lasting 3 years is not uncommon for each of the 8 South African rainfall regions defined by the South African Weather Service. Combining the retrospective analysis with real time monitoring could be extremely beneficial in the development of response, mitigation strategies and awareness plans.
\end{abstract}

Keywords: South African drought, drought monitoring, El Nino, climate change

\section{Introduction}

Drought is a regular and recurrent feature of South African climate. A drought is a shortage of precipitation over an extended period. Its impact on society depends on its intensity but also on its duration. Over Southern Africa, the recent period (since 1970) is characterised by strong interannual rainfall variability. In particular, countries experienced more intense and more widespread droughts (Richard et al., 2001). A common time-scale for agricultural droughts is the season (3 to 6-month time scales) when deficiency in precipitation results in damage to crop (Harsch, 1992). Studies of the normalised vegetation index dataset (Los et al., 1994) show that the impact of droughts on vegetation (Farrar et al., 1994) is particularly strong where annual rainfall amount varies from 300 to $500 \mathrm{~mm}$ (Richard and Poccard, 1998). This is the case for most of South Africa. Hydrological drought is associated with precipitation shortage on a longer time scale (12 months to 2 years or more) and its effect on surface or subsurface water supply (Meigh et al., 1999). Although all droughts originate from a lack of precipitation, hydrologists want to know how the precipitation shortage influences the hydrological system. As a result hydrological or agricultural drought can be out of phase and their impacts on various economic sectors can be appreciably different. It takes longer for precipitation shortage to become evident in soil moisture, streamflow, groundwater and dam levels. It is therefore useful to define a drought index that will represent different time scales from 3 months to 2 years.

Hayes et al. (1999) used the standardised precipitation index (SPI) to monitor the 1996 drought in the United States of America.

\footnotetext{
* To whom all correspondence should be addressed.

畕 +2721 6503607; fax: +2721 6503979;

e-mail: rouault@ocean.uct.ac.za

Received 15 May 2002; accepted in revised form 30 July 2003.
}

They show how the SPI can be used operationally to detect the start of a drought, its spatial extension and temporal progression Hayes et al. (1999) shows that the onset of the drought in the USA in 1996 could have been detected one month in advance of the Palmer Drought Severity Index (PSDI). The PDSI (Palmer, 1965) is the most used index in the USA but has some limitation (Guttman, 1998; McKee et al, 1995). Although it is quite a recent index, the SPI was used in Turkey (Komuscu, 1999), Argentina (Seiler et al;, 2002), Canada (Anctil et al.; 2002), Spain (Lana et al.; 2003), Korea (Min et al.; 2003), Hungary (Domonkos, 2003), China (Wu et al.; 2001) and Europe (Lloyd-Hughes and Saunders; 2002) for real time monitoring or retrospective analysis of droughts. The SPI is consistent with regard to the spatial distribution of rainfall that occurs with great variability in South Africa due to geographical location, orography and the influence of the oceans. Using that index to develop a climatology of the spatial extension and intensity of droughts gives also an additional understanding of its characteristics and an indication of the probability of recurrence of drought at various levels of severity.

The main goal of this paper is to present the SPI and its potential use for real time monitoring of spatial extension and intensity of droughts in South Africa. Because we can learn from past events or compare real time with similar past conditions, the SPI of the 93 SAWS (South Africa Weather Service) rainfall districts at different time scales was calculated at the end of every month since 1922 and displayed on a chart of South Africa. This atlas is available on a web site (http://www.egs.uct.ac.za/ rouault/spil.html). An extract from the atlas displays the intensity and spatial extension of the 20 worst droughts since 1922 at the 6-month scale at the end of April. Another one show the conditions at different time scale at the end of December 1982, beginning of the most severe drought since 1921 according to the SPI. The last part of the paper show that the SPI is also valuable when studying the interannual and interdecadal variability of rainfall in South Africa and provide new insights on the topic. 

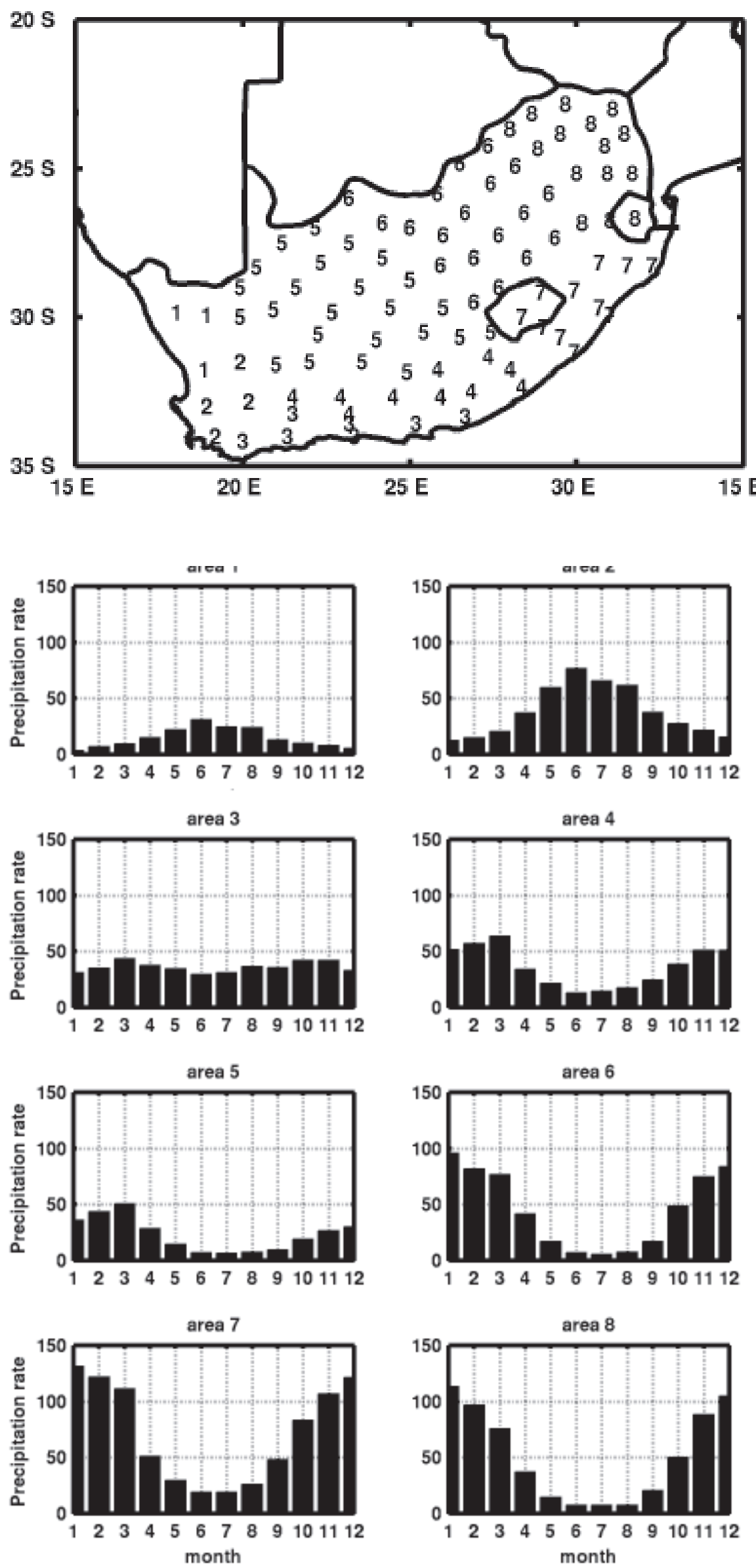

\section{Complexity of the rainfall regimes in South Africa}

The SAWS divides the country into 93 rainfall districts. Each district combines an average of typically 5 to 15 rain-gauge stations. The 93 districts are parts of 8 climatic regions. Those regions were determined by the SAWS based on a cluster analysis of South African rainfall (South African Weather Bureau, 1972). Figure 1 shows the location of the 8 areas and the 93 districts and table 1 presents the names of the 8 regions.

Figure 2 shows the mean yearly cycle for those 8 areas. The North-Western Cape has very little rainfall with a winter maximum (June) of $30 \mathrm{~mm}$ (Fig. 2a). The South Western Cape has also most of its rain in June but differs with a maximum of $70 \mathrm{~mm}$ (Fig. 2b). Both Areas 1 and 2 constitute the winter area region. South Coast (Area 3) experiences regular rainfall all year long from about $30 \mathrm{~mm}$ to $40 \mathrm{~mm}$ (Fig. 2c). The next five areas represent the summer rainfall region. The Southern Interior (Area 4) has its maximum rainfall in late summer (March) with about $60 \mathrm{~mm}$ (Fig. 2d). The Western Interior (Area 5) has also its rainfall maximum in March, with about $60 \mathrm{~mm}$ (Fig. 2e), but differs from the Southern Interior because of its very dry winter. The Central Interior (Area 6), KwaZulu-Natal (Area 7) and the North-Eastern Interior (Area 8) have a maximum rainfall in January. KwaZulu-Natal (Fig. 2g) is the wettest area with maximum in January (130 $\mathrm{mm}$ ), and the North-Eastern Interior (Fig. 2h) has the biggest difference between summer and winter. Therefore, a deficit of rainfall of $10 \mathrm{~mm}$ for a given month could be considered as a drought in one area (Area 1 for example) but not in another (Area 7).

Figure 1 (top left)

Location of the 93 districts of the South African Weather Service rainfall dataset used in the study. Number represents the 8 homogeneous rainfall area defined by SAWS: North-Western Cape (1); SouthWestern Cape (2), South Coast (3), Southern Interior (4), Western Interior (5), Central Interior (6), KwaZulu-Natal (7), North-Eastern Interior (8).

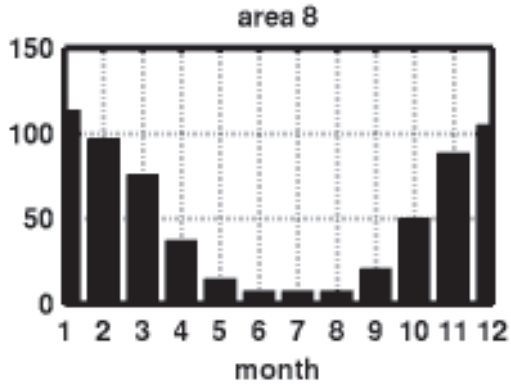

Figure 2 (bottom left) Mean 1921-2001 monthly precipitation rate $(\mathrm{mm} / \mathrm{month})$ for the 8 SAWS homogeneous rainfall areas. From left to right and top to bottom: North-Western Cape; South-Western Cape, South Coast, Southern Interior, Western Interior, Central Interior, KwaZulu-Natal, NorthEastern Interior. 
In the same way, a reduction of $20 \%$ of rainfall in some area and different season (Area 8 in summer for example) can represent a huge difference in water storage deficiency, but not in another (Area 2 in summer). Moreover, a percentage from normal is difficult to interpret in terms of impact. Given those areas, with different precipitation and difference in seasonal behaviour, it is clear that a precipitation total could lead to a drought in some area while for others it will be near normal. Because precipitation associated with droughts in one area or one season corresponds to flood in others areas or another season, the temporal and spatial differences of rainfall in South Africa make it difficult to represent a coherent picture. Furthermore, the onset of the rainy season and the timing of maximum rainfall are different for the 8 areas making water management and mitigation of agricultural or hydrological drought difficult. A problem using normalised anomalies (difference from the mean divided by standard deviation) is that the normalised anomaly is not symmetrical (positively skewed) because flood leads to a bigger anomaly from the mean than drought. The SPI addresses those problems because it is normalised in time and in space.

\section{Standardised Precipitation Index}

McKee et al. $(1993,1995)$ from the Colorado Climate Centre formulated the SPI in 1993. In summary, the SPI allocates a single numeric value to the precipitation ( -3 to 3 ), which can be compared across regions with different climates. The SPI was designed to state that it is possible to simultaneously experience wet conditions on one or more time scales, and dry conditions at other time scales. The SPI is based on the probability of precipitation for a given time period. Technically, the SPI is the number of standard deviations that the observed value would deviate from the long-term mean, for a normally distributed random variable. Since precipitation is not normally distributed, a transformation is first applied so that the transformed precipitation values follow a normal distribution. The SPI allows to determine the probability occurrence of dry or wet events at different time scales (from 3 monthly to two yearly mean rainfall). The SPI can be used on all stations having more than 30 years of rainfall (Hayes et al., 1999). The climatological rainfall distribution at any station or ensemble of nearby station can be represented by a gamma distribution. The gamma distribution can be described by its frequency or probability distribution. The precipitation rate is fitted to a gamma distribution for different time scales ( 3 months, 6 months, 12 months, and 24 months) for each month of the year. The resulting function can be used to find the cumulative probability of a rainfall event for a station for a given month of the dataset and at different time scale of interest (Table 2).

Thus an SPI of 2 or more happens about $2.3 \%$ of the time and a normal condition (SPI between 1 and-1) happens $68.2 \%$ of the time. This allows establishing a classification values for SPI values (Table 3).

A SPI of -2.00 and less will identify a extreme drought that happens twice per century; from -1.5 to -1.99 about 4 times per century; from -1 to -1.5 about 9 times per century. An SPI of 0 to -1 will be related to normal or slightly below normal condition happening 34 times per century. Detail of the SPI algorithm can be found in Guttman (1998;1999), McKee et al. (1993; 1995) and Hayes et al. (1999). The SPI has been favourably evaluated and compared with others indices (Keyantash and Dracup, 2002) and is now integrated in the set of indices used by the Drought Monitor in the USA (Svoboda et al., 2002). Because the SPI is linked to percentage of occurrence and based on rainfall only, it can be used in others countries.

\section{TABLE 1}

The 8 climatic areas defined

by the South African Weather

\begin{tabular}{|l|l|} 
Number & Name \\
\hline 1 & North-Western Cape \\
2 & South-Western Cape \\
3 & South Coast \\
4 & Southern Interior \\
5 & Western Interior \\
6 & Central Interior \\
7 & KwaZulu-Natal \\
8 & North-Eastern Interior \\
\hline
\end{tabular}
Service (SAWS)

\begin{tabular}{|c|c|}
\hline \multicolumn{2}{|c|}{$\begin{array}{l}\text { TABLE1 } \\
\text { SPI and Corresponding } \\
\text { cumulative probability in } \\
\text { relation to the base } \\
\text { period (Hayes et al, 1999) }\end{array}$} \\
\hline SPI & $\begin{array}{r}\text { Cumulative } \\
\text { Probability }\end{array}$ \\
\hline-3.0 & 0.0014 \\
\hline-2.5 & 0.0062 \\
\hline-2.0 & 0.0228 \\
\hline-1.5 & 0.0668 \\
\hline-1.0 & 0.1587 \\
\hline-0.5 & 0.3085 \\
\hline 0.0 & 0.5000 \\
\hline+0.5 & 0.6915 \\
\hline+1.0 & 0.8413 \\
\hline+1.5 & 0.9332 \\
\hline+2.0 & 0.9772 \\
\hline+2.5 & 0.9938 \\
\hline+3.0 & 0.9986 \\
\hline
\end{tabular}

\begin{tabular}{|l|l|l|}
\hline \multicolumn{3}{|c|}{ TABLE2 } \\
SPI classification (Hayes et al., 1999) \\
\hline SPI Value & Drought category & Occurrence \\
\hline 2.00 and above & Extremely wet & $2.3 \%$ \\
1.5 to 1.99 & Very wet & $4.4 \%$ \\
1. to 1.49 & Moderately wet & $9.2 \%$ \\
-0.99 to 0.99 & Near normal & $68.2 \%$ \\
-1.00 to -1.49 & Moderately dry & $9.2 \%$ \\
-1.50 to -1.99 & Severely dry & $4.4 \%$ \\
-2.00 and less & Extremely dry & $2.3 \%$ \\
\hline
\end{tabular}

We have calculated the SPI for a precipitation total ranging between 3 months and 2 years for each of the 1921 to 2001 SAWS 93 districts rainfall data using the techniques developed by Hayes et al. (1999). The 3-month SPI can be used to characterise a seasonal drought index well suited to describe the beginning, the heart or the end of the rainy season. The total rainy season can be described using the 6-month index and 12-month and 24-month SPI can be used for long-term drought. The $\mathrm{X}$-month SPI $(X=3,6,12$ or 24$)$ is used to compare the precipitation over a specific $\mathrm{X}$-month period with the precipitation totals from the same period for all the years of the dataset.

\section{Spatial extension of droughts}

\section{SPI calculated for December 1982}

3-month SPI uses the precipitation total of October, November and December 1982 while the 6-month SPI calculated for December 1982 use the precipitation total of July 1982 to December 1982 (Fig. 3). A 3-month SPI can be used to monitor soil moisture conditions at the start of the growing season or precipitation during the different stages of plant development or reproduction. The 3-month SPI for the end of December 1982 (Fig. 3) showed a deficit in rainfall in the North-Eastern Interior. However, dry conditions in the summer rainfall South African regions began in 1982, as can be seen in the 

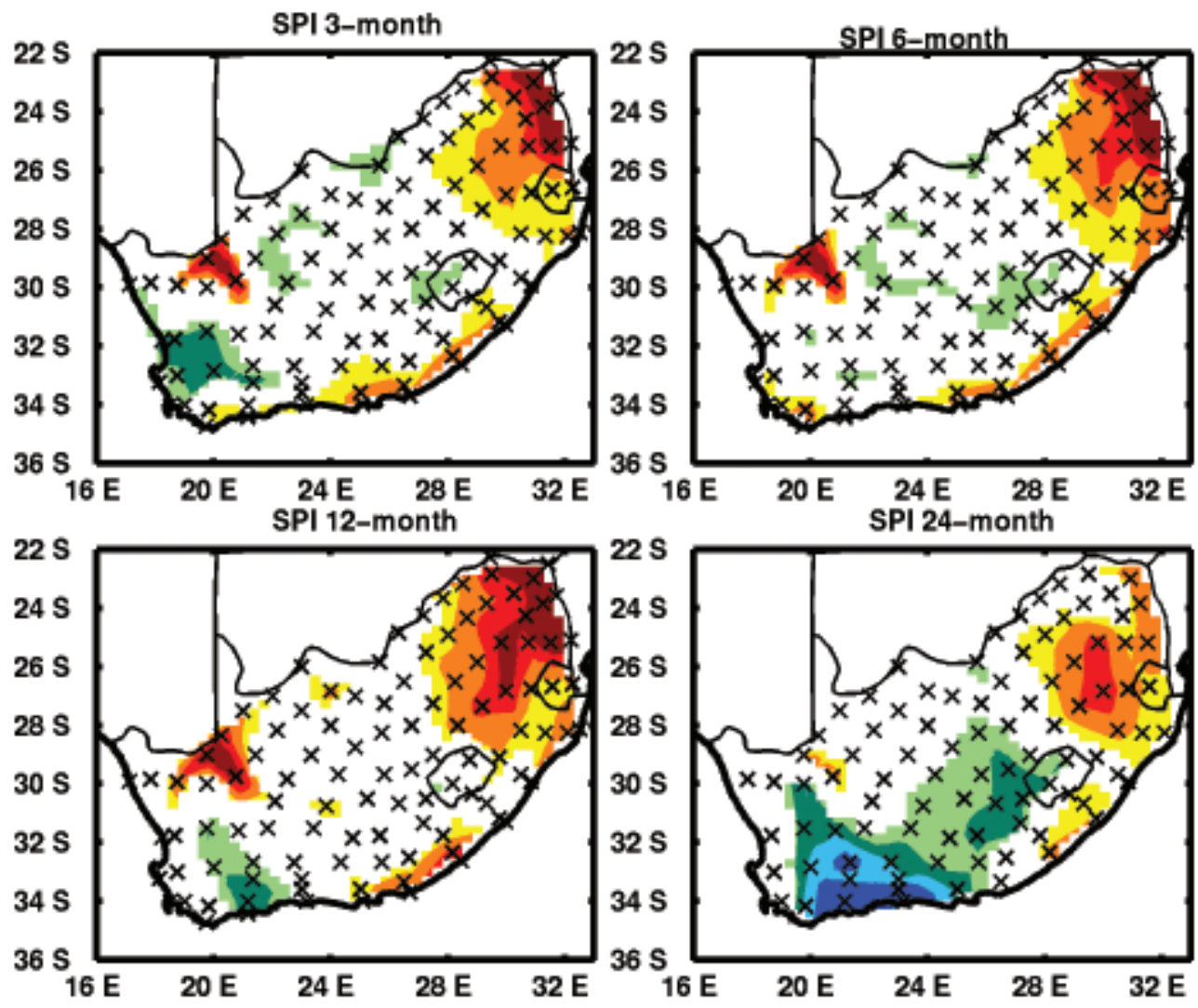

Figure 3

Spatial extension of the SPI at 3, 6, 12 and 24 month time scale at the end of December 1982. Colour code: brown (-3 to -2$)$, red $(-2$ to -1.5$)$, orange $(-1.5$ to -1$)$, yellow (-1 to-0.5), dark blue (3 to 2), light blue (2 to 1.5), dark green (1.5 to 1), green (1 to 0.5) 12-month and 24-month SPI. In fact the 12-month SPI is more intense that the 3-month SPI due to dry condition in 1982. A study of the SPI for the 1981 and 1982 shows some serious deficit at the 6-month scale for the Northeast part of South Africa and more widespread dry condition at the 3-month scale at the end of March 1982. The evolution of the 3-month SPI for each month of the summer rainy season in $82 / 83$ shows dry to extreme dry condition at the end of December 82 in the Northeast and along the East coast increasing and spreading to all summer rainfall areas during that season. Comparison with other rainy season shows that the start of the rainy season was one of the worse since 1922. Interestingly one can note that the coastal regions were experiencing a drought at the 3-month scale but wetter conditions at the 2-year scale. In that region in spite of a bad start of the year, water storage must have been plentiful.

The 3-month and 6-month SPI may be misleading in regions where it is normally dry during a 6-month period. For instance the 6-month SPI at the end of December 1982 resembles the 3-month SPI. During the dry season large negative or positive SPIs may be associated with precipitation totals not very different from the mean. This caution can be demonstrated with the climate of Western Cape, where very little rain falls from November to March.. Because this is a period with little rain, these mean totals will be small and relatively small deviations on either side of the mean could have large negative or positive SPI(Fig. 6). Nevertheless, it is important to have a drought index for longer time scales. A normal 3-month period could occur in the middle of a longer-term drought that would only be visible at longer time scales.

\section{SPI calculated for the 80 districts representing the summer rainfall season}

The SPI when applied to the 80 districts representing the summer rainfall season (Areas 4 to 8 ) allows a particular classification of droughts at different time scale as a function of the number of districts within a certain range. Fig. 4 shows the spatial extension and intensity of 20 of the worst droughts experienced in the summer rainfall area since 1922. In 1926, 1933, 1945, 1949, 1952, 1970, 1983 and 1992 more than half of the 80 summer rainfall districts had an SPI $<-1$. The 3-month SPI can be used to look at the beginning or the end of the rainy season. For instance in 1973, there were 60 dry districts at the end of January at the 3 months scale but good late season rainfall (no dry district at the end of April at the 3-month scale) mitigated the drought. Likewise in 1922, there was no dry district at the 3-month scale at the end of January but a dry late season brought the total of dry districts at the 3-month scale to 50 . The 3-month and 6-month SPI show that 1982/1983 was the worst drought since 1922 according to that index.

\section{Time series}

\section{3, 6, 12 and 24-month SPI}

The SPI can be used in a time series to compare real time with SPI of the previous 80 years. Figures $5 \mathrm{a}, \mathrm{b}, \mathrm{c}$ and d show the SPIs at the end of March since 1922 for the summer rainfall regions at the heart of the rainy season (Areas 4, 6, 7 and 8). Fig.s 5e and f show the SPIs at the end of August for the winter rainfall (Areas 1 and 2). The SPI is symmetrical for occurrence of wet and dry events. It represents an advantage on the normalised anomaly (anomaly from the mean divided by standard deviation) where wet anomalies have a higher absolute value. This gives us a climatology of major drought and wet spells at different time scales. For Area 4 (Fig. 5a) the worst drought at the 2-year scale was in 1946 and 1947. Neither normalised anomaly (not shown) nor a 3-month SPI at the end of March indicates the severity of the situation. Dry conditions persisted in Area 6 in summer for 1982, 1983 and 1984. Figure 5 illustrate the fragility of South Africa as far as rainfall is concerned. At the 2-year scale Area 6 recovered from the drought at all scales only during 1998. Extended wet or dry period seems to be the rule for all areas. Looking at Fig. 
1922

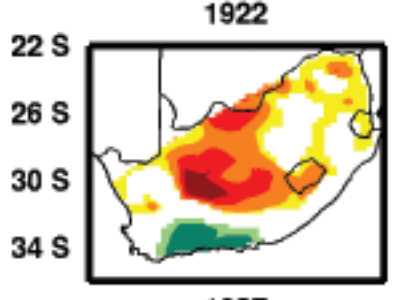

1927

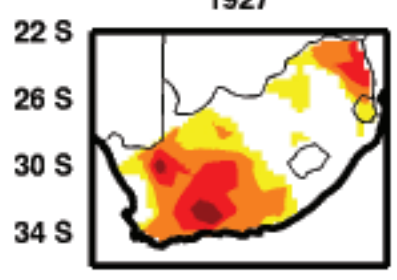

1945

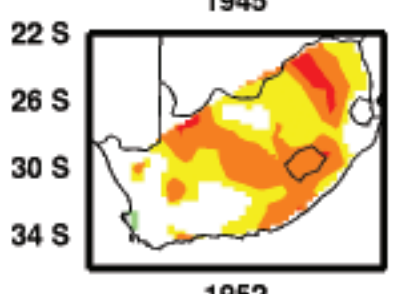

1952

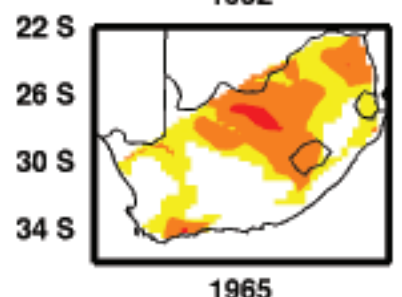

1965

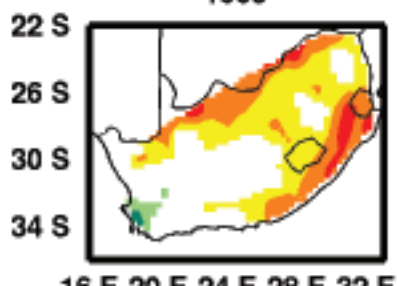

16 E 20 E 24 E 28 E 32 E
1926

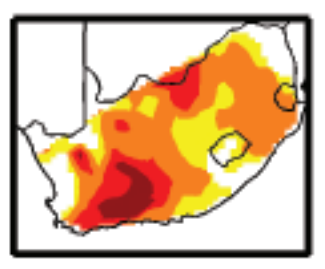

1933

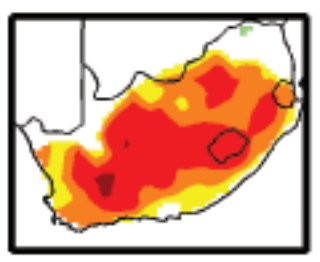

1949

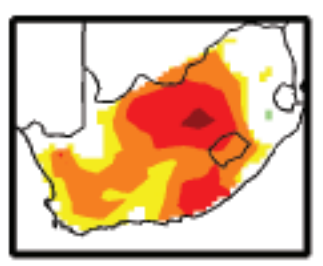

1964

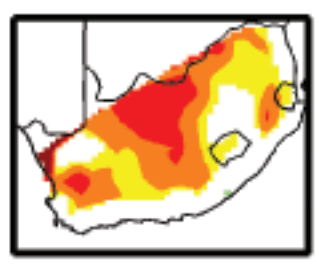

1966

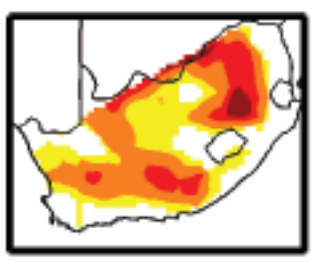

16 E 20 E 24 E 28 E 32 E

Figure $4 a$

Spatial extension of the 6-month SPI at the end of April for 10 of the worst dry years in South Africa since 1922. Colour code: brown (-3 to -2$)$, red (-2 to -1.5$)$, orange $(-1.5$ to -1$)$, yellow $(-1$ to-0.5), dark blue (3 to 2), light blue (2 to 1.5), dark green (1.5 to 1$)$, green (1 to 0.5$)$.

5 , there is reason to believe that other multi-year dry spells could happen. The wet season during the La Niña event of 2000 is the wettest of the time serie for North-Eastern Interior (Area 8) and there is a drought during the 1998 El Niño that is apparent only in that area. Extended dry or wet period can be seen through the time series at the 1-year and 2-year scales.

\section{Monitoring month to month}

The SPI can be also used in a time series to look at the real time evolution of the SPI. Fig. 6 shows the SPI for the South Western Cape at the end of every month from 1994 to 2001 at different time scales. This shows how the SPI can be used operationally to monitor the start and end of dry or wet period at different time scale. It can be seen that the heavy rain of the winter 2002 is showing a 3-month SPI $>1$ from July to October 2002 but due to below-normal rainfall in 1999, 2000 and most of 2001 one-year and two-year SPIs are not

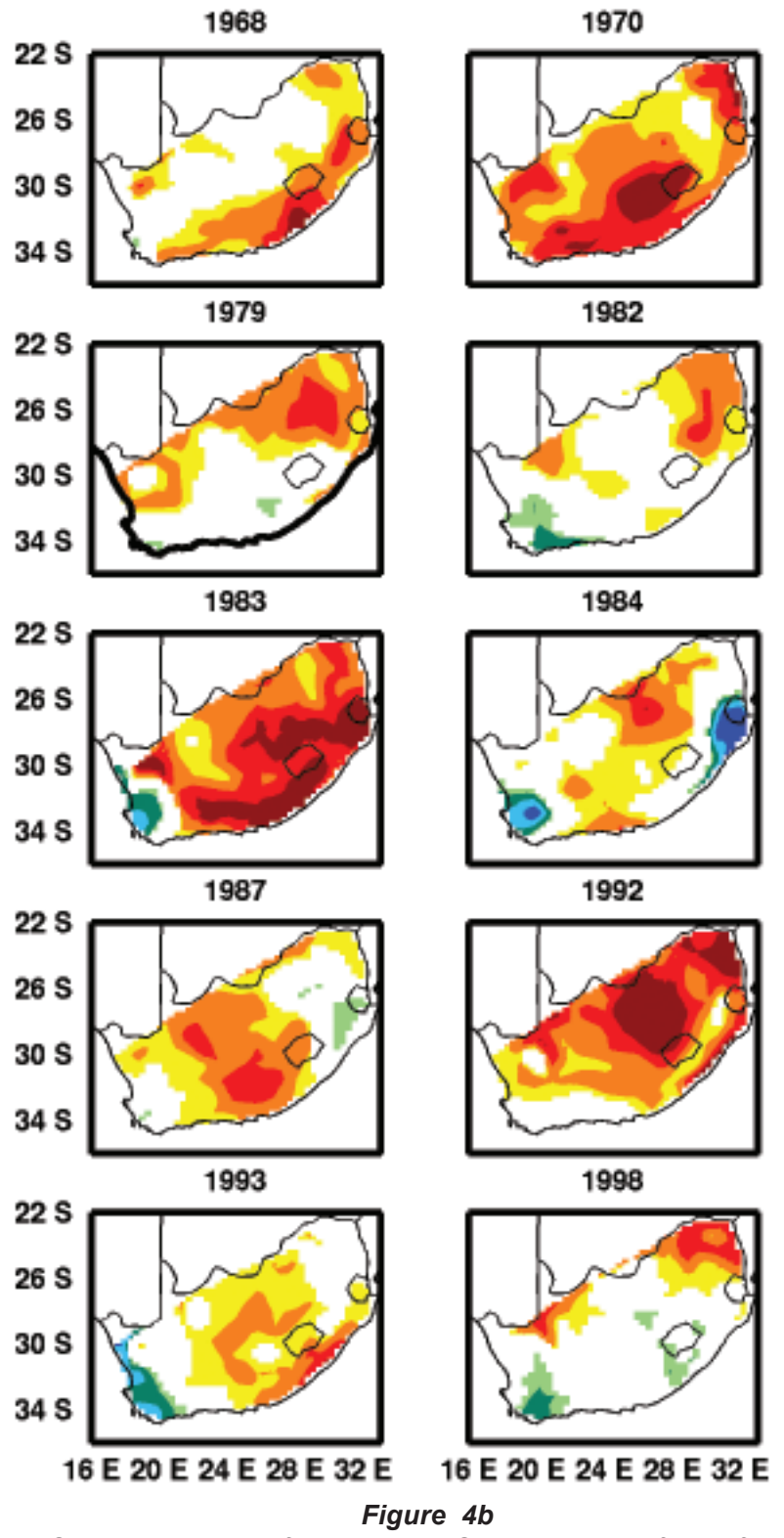

Spatial extension of the 6-month SPI at the end of April for 10 of the worst dry years in South Africa since 1922. Colour code: brown (-3 to -2$)$, red (-2 to -1.5$)$, orange (-1.5 to -1$)$, yellow (-1 to-0.5), dark blue (3 to 2), light blue (2 to 1.5), dark green (1.5 to 1$)$, green (1 to 0.5$)$.

as high as one would think. In fact the 2-year SPI is higher from winter 1996 to winter 1998. Looking at Fig. 6 it is not surprising to understand why dam levels in summer 96/97 in the Western Province were higher that in 2001/2002 in spite of a 20 year maximum for winter rainfall in 2001. We also note that this decade did not have some serious droughts. For operational use, caution must be used when using the SPI in summer months when a flood can create a high SPI index. Hayes et al. (1999) have shown that for some regions a good rainfall for one month can create the impression that the drought is over but until the SPIs are not above a certain value at all scales (typically -1) a drought will still affect a region one way or another.

\section{Decadal variability of summer rainfall}

More attention should be pay to decadal variability of rainfall in order to produce accurate seasonal forecast and for a better manage- 
SPI 3-month for areo 4 at the end of March
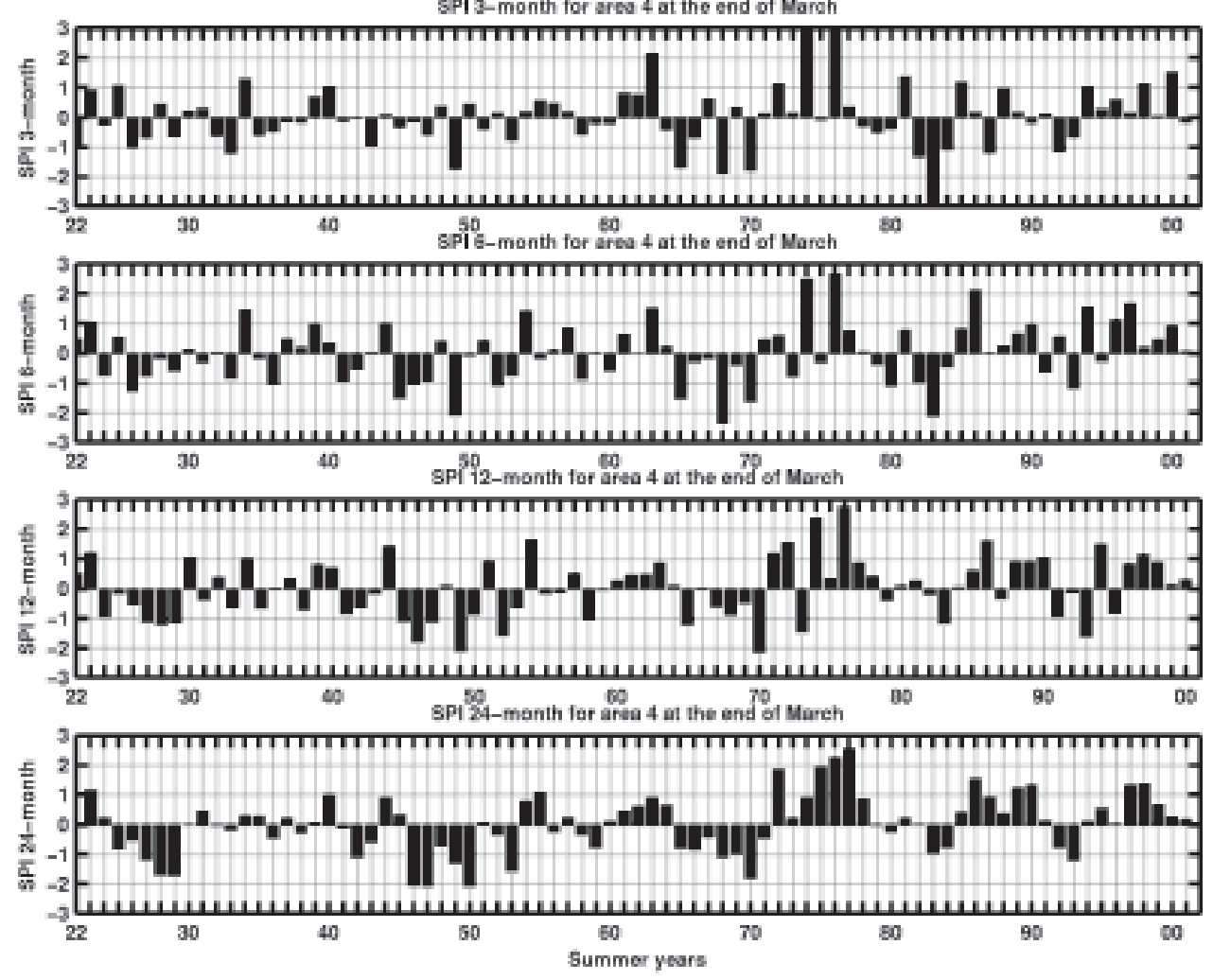

Figure 5a

Standardised Precipitation Index at the 3, 6, 12 and 24 months time scale (top to bottom) at the end of March for Southern Interior from 1922 to 2001
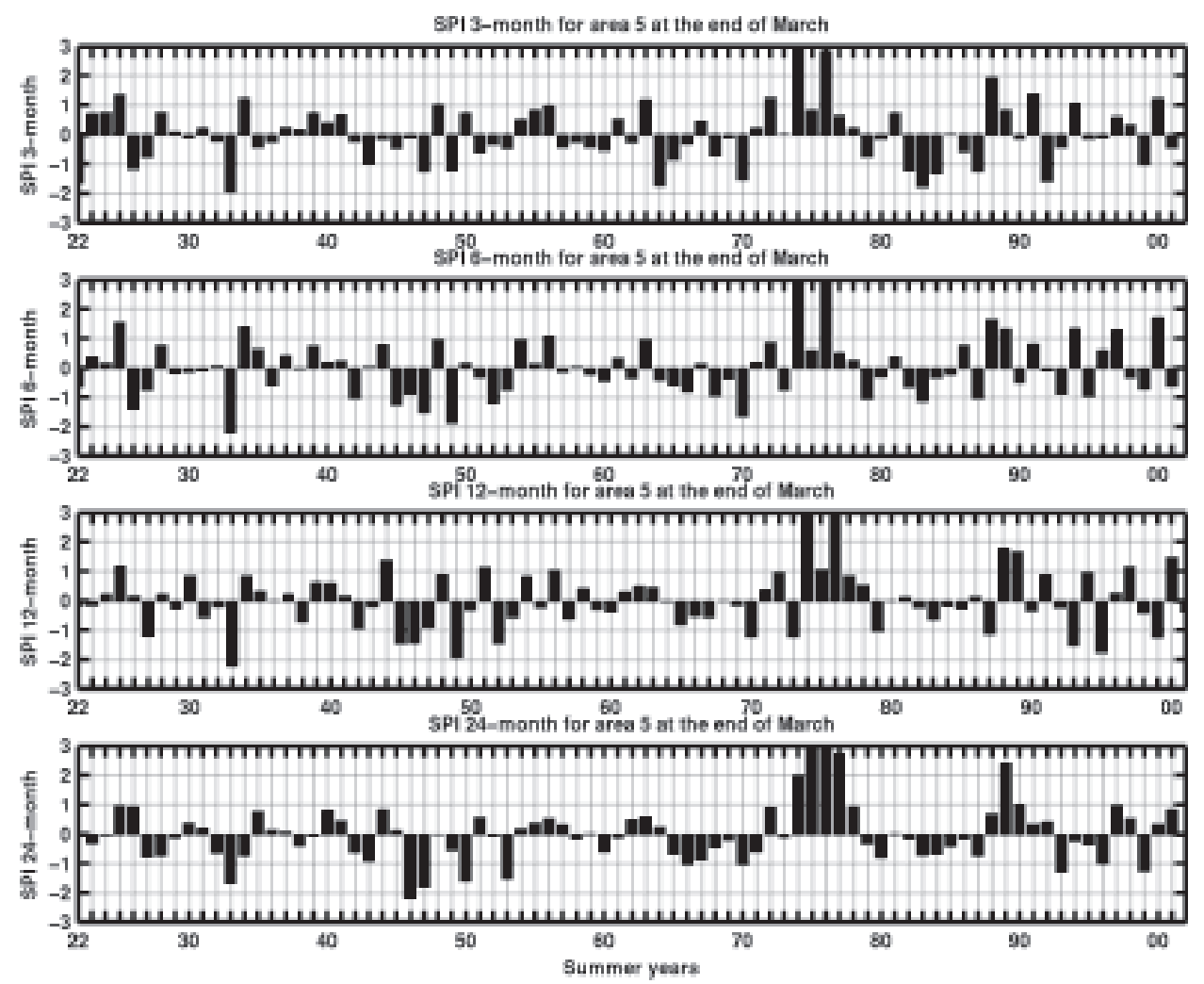

Figure $5 b$

Standardised Precipitation Index at 3, 6, 12 and 24 months time scale (top to bottom) at the end of March for Western Interior from 1922 to 2001. 
SPI 3-month far area 6 at the end of Merch
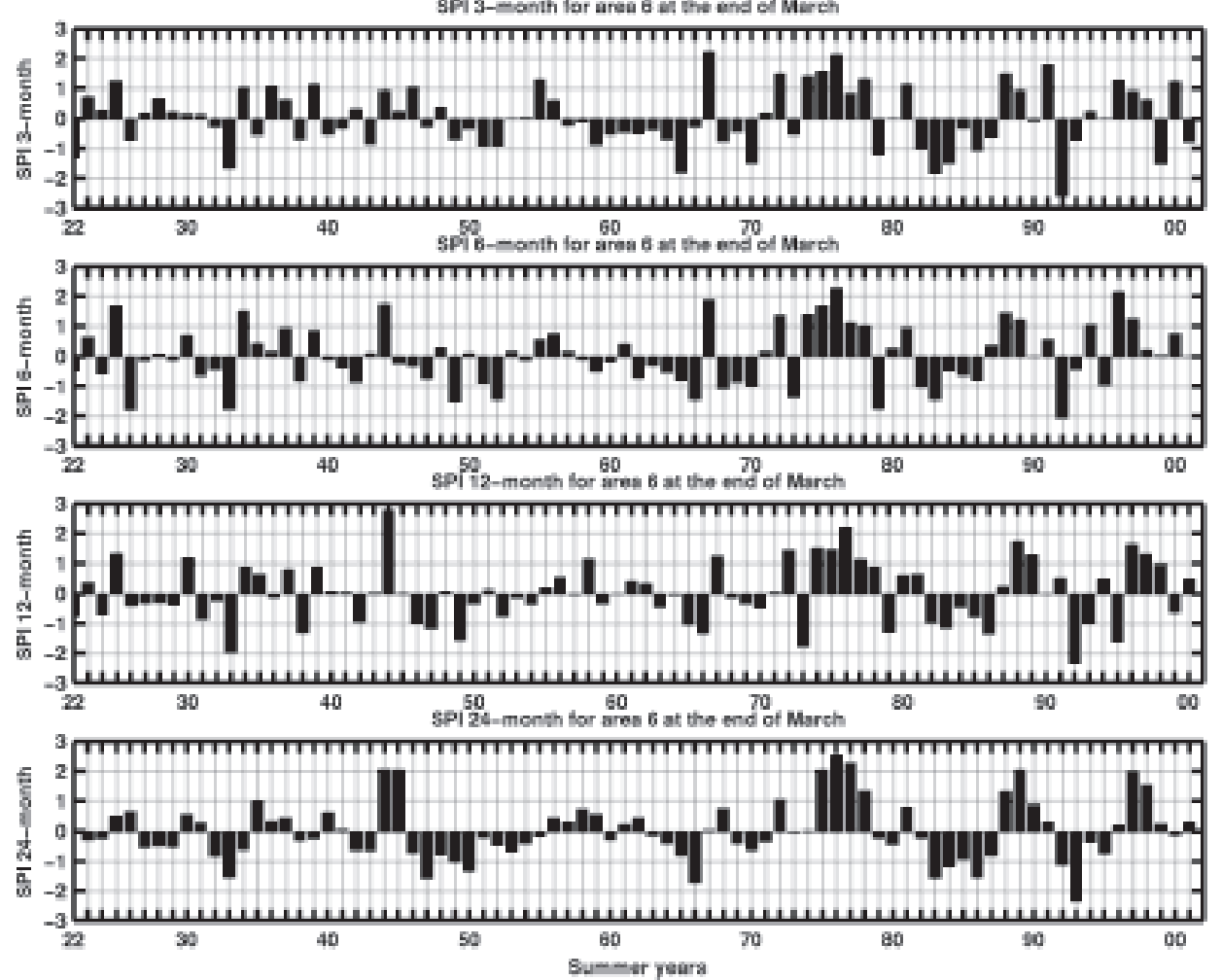

Figure $5 c$

Standardised Precipitation Index at 3, 6, 12 and 24 months time scale (top to bottom) at the end of March for Central Interior from 1922 to 2001.
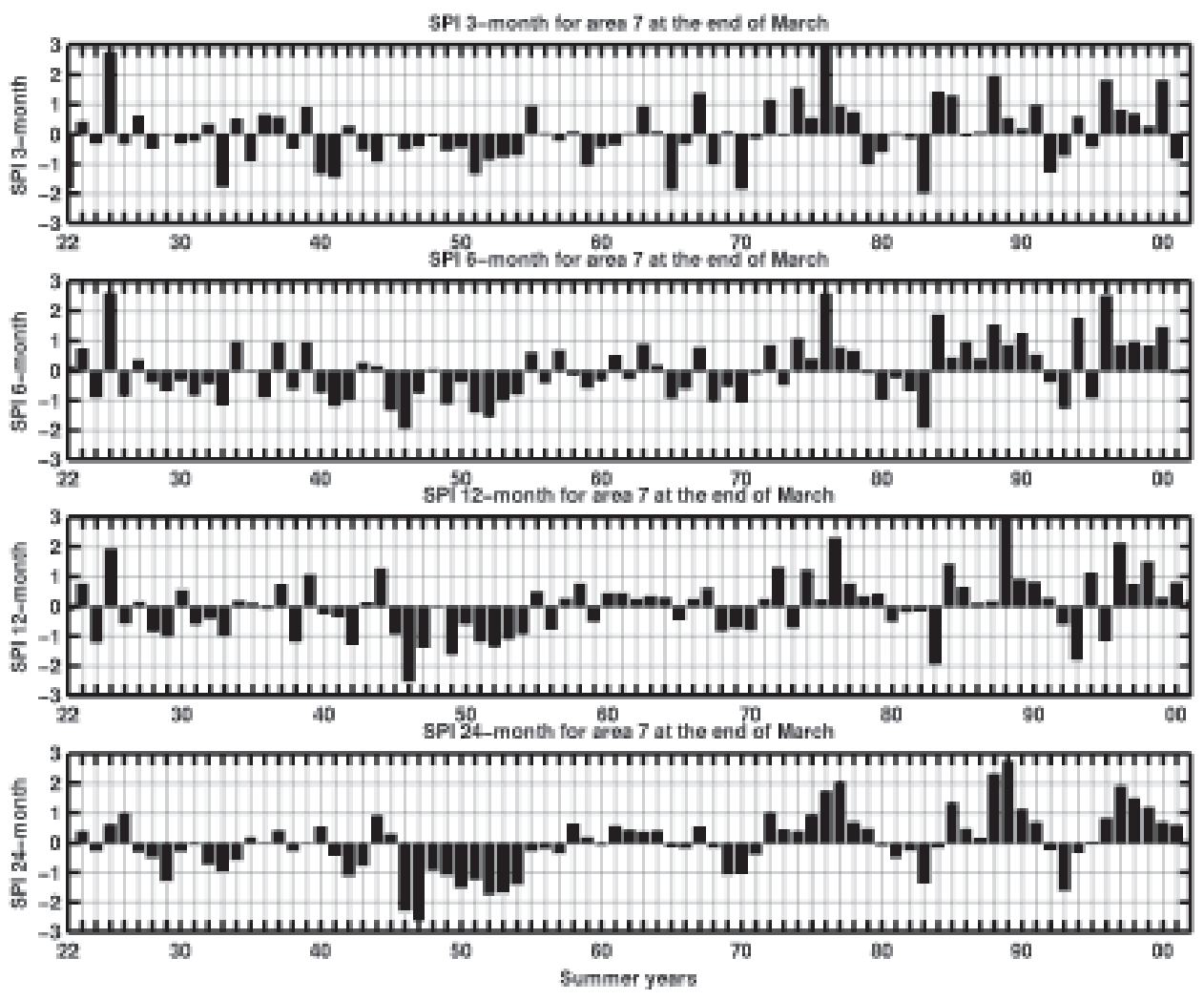

Figure $5 d$

Standardised Precipitation Index at 3, 6, 12 and 24 months time scale (top to bottom) at the end of March for KwaZulu-Natal from 1922 to 2001. 
SPI 3-month for area 8 at the end of Maroh
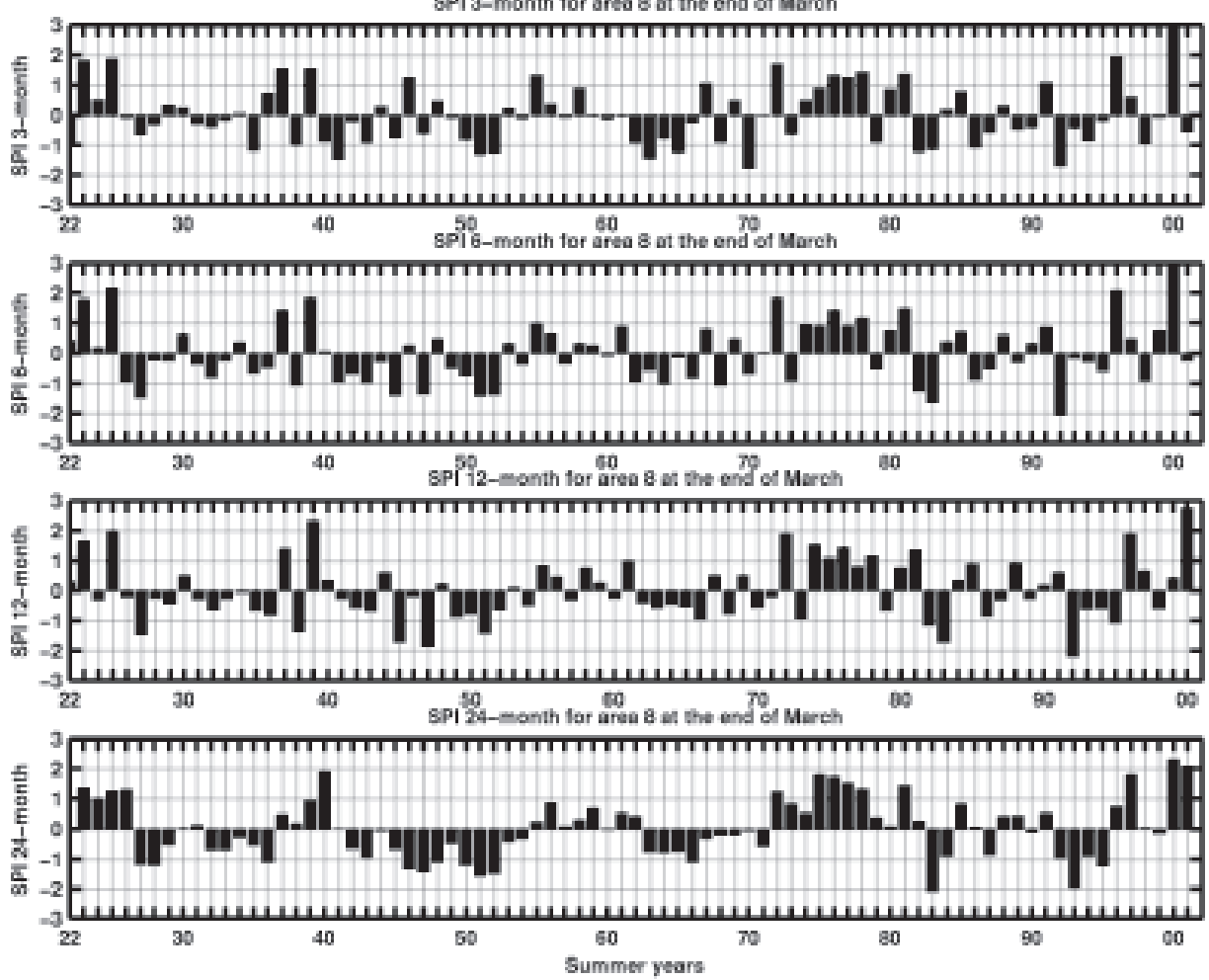

Figure $5 e$

Standardised Precipitation Index at 3, 6, 12 and 24 months time scale (top to bottom) at the end of March for North-Eastern Interior from 1921 to 2001.
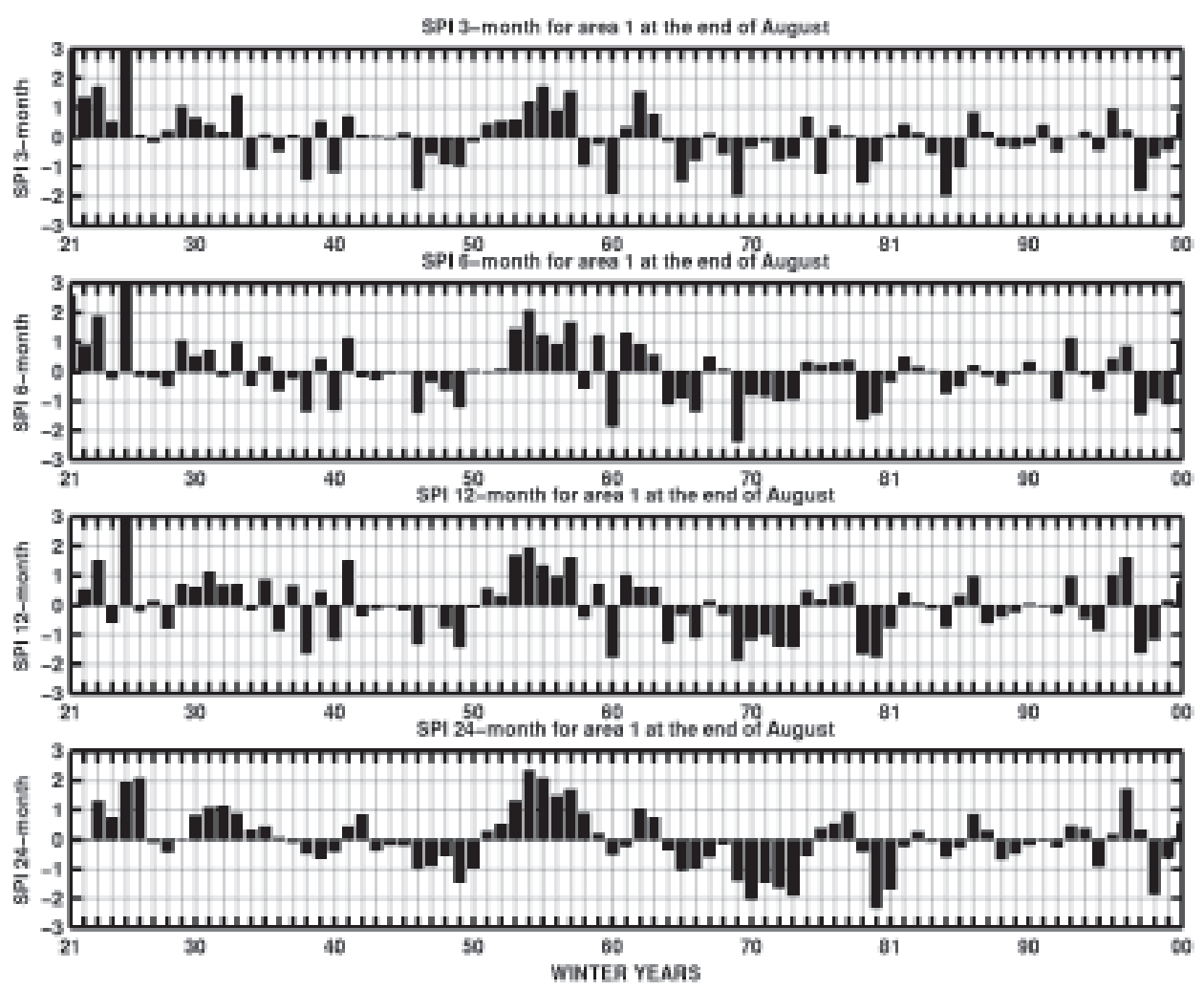

Figure $5 f$

Standardised Precipitation Index at 3, 6, 12 and 24 months time scale (top to bottom) at the end of August for North-Western Cape from 1922 to 2001. 
SP1 3-month for area 2 at the end of August
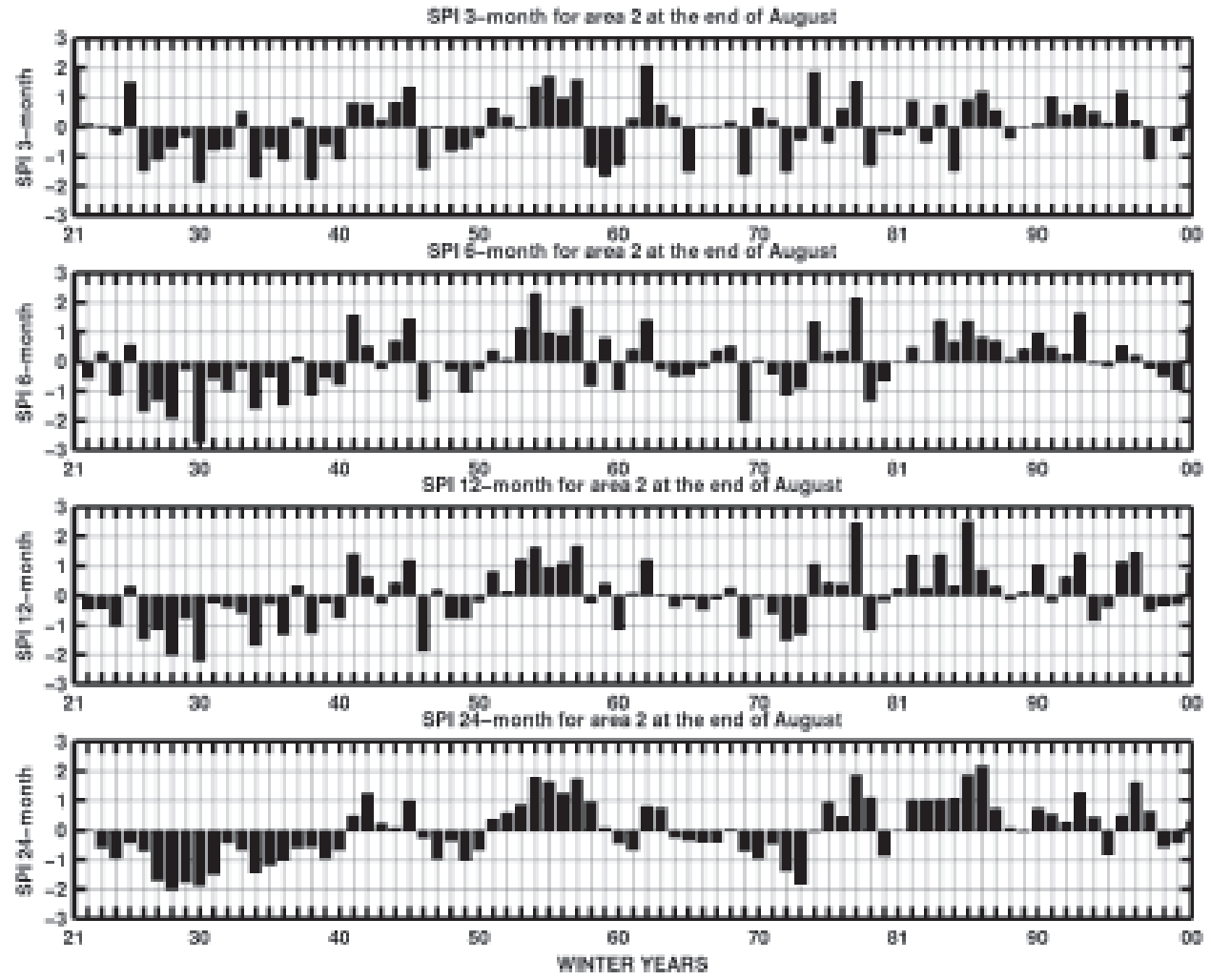

Figure $\mathbf{5 g}$

Standardised Precipitation Index at 3, 6, 12 and 24 months time scale (top to bottom) at the end of August for South-Western Cape from 1922 to 2001.
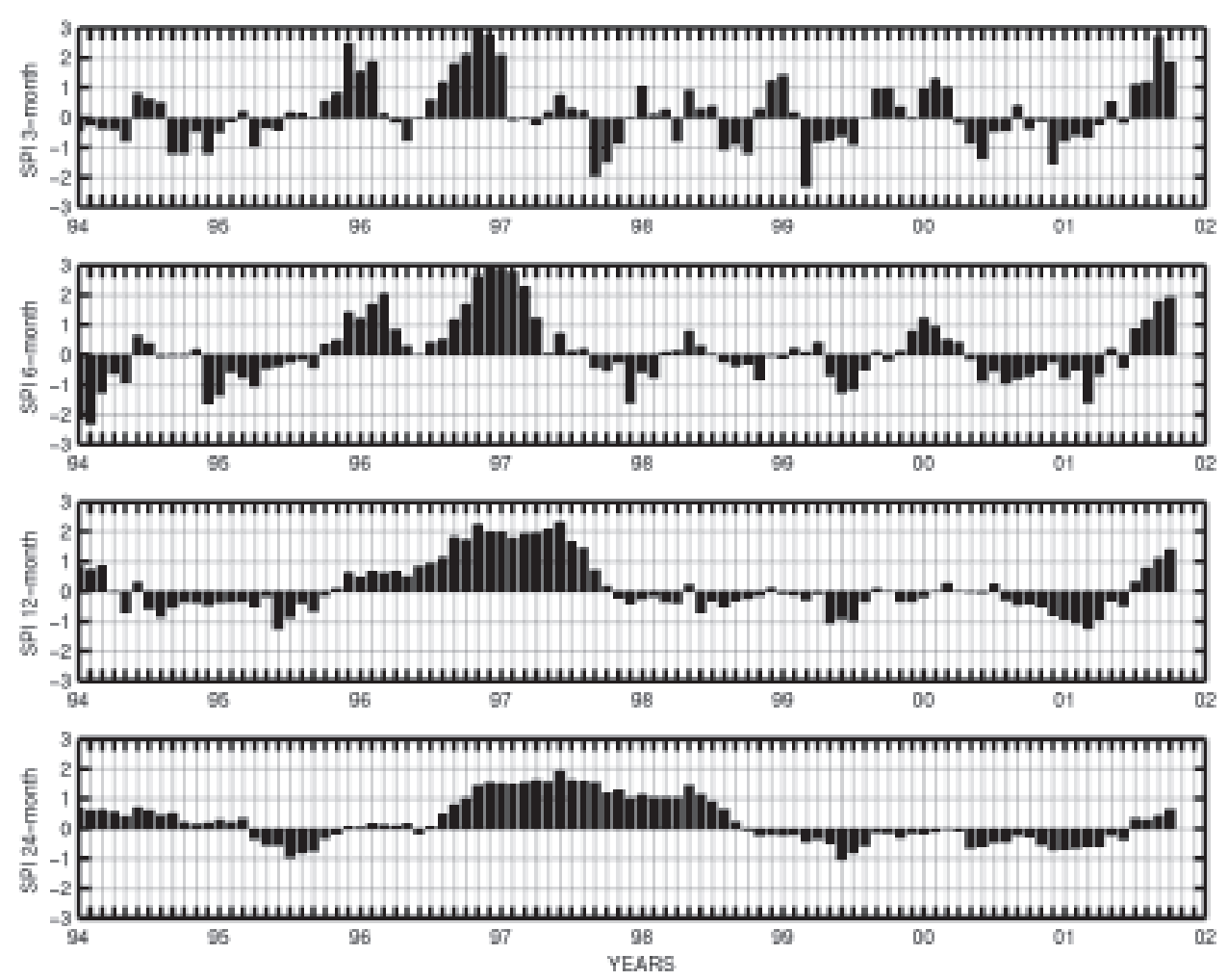

Figure 6

Standardised Precipitation Index at 3, 6, 12 and 24 months time scale (top to bottom) for South-Western Cape (Area 2) at the end of every month from January 1994 to October 2001. 


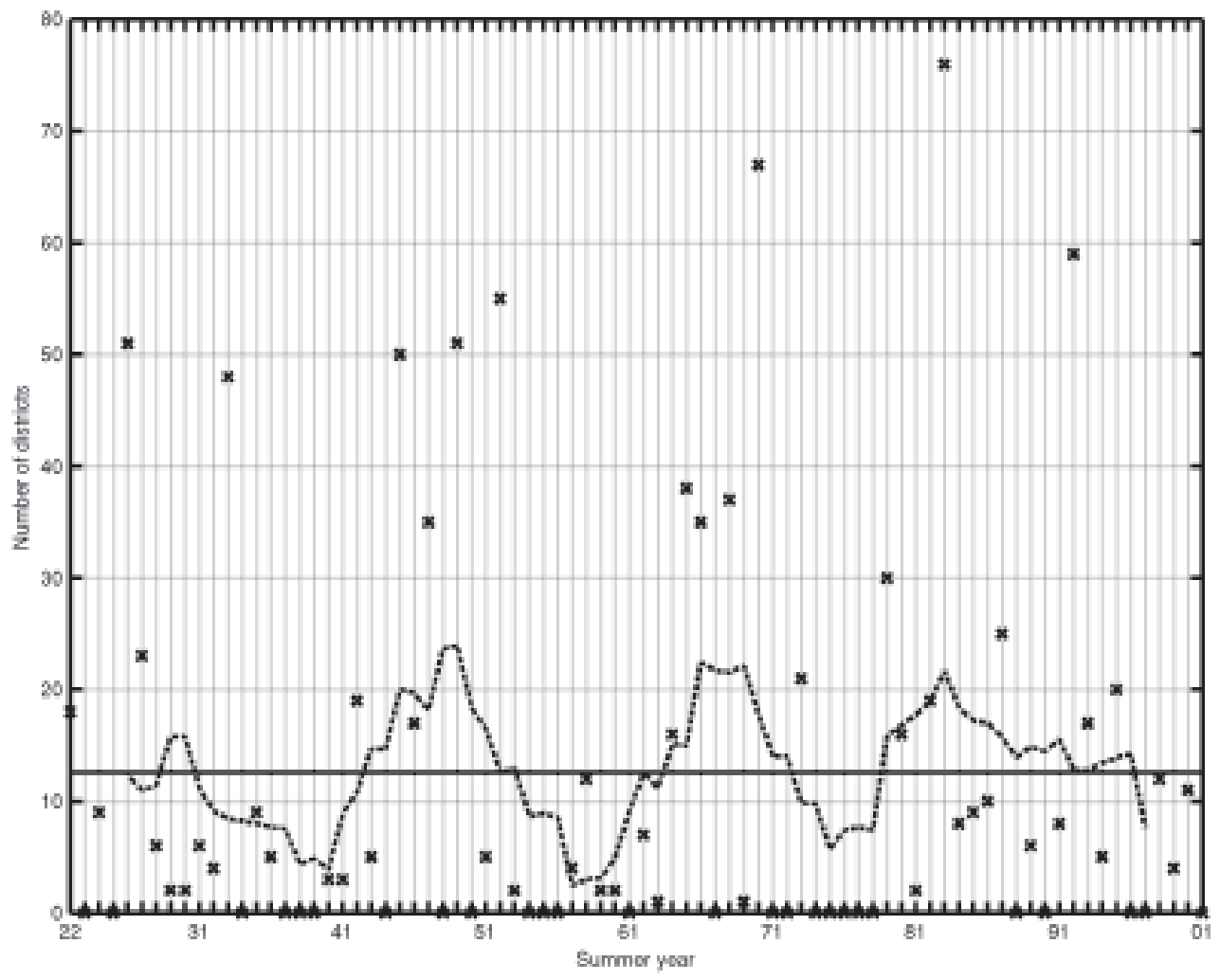

Figure 7

Number of dry districts (SPI 6-month <-1) for the 80 summer rainfall districts (Area 4 to 8) at the end of April with 9-year window running mean (dashed line) and 1922-2001 mean number of dry districts (solid line).

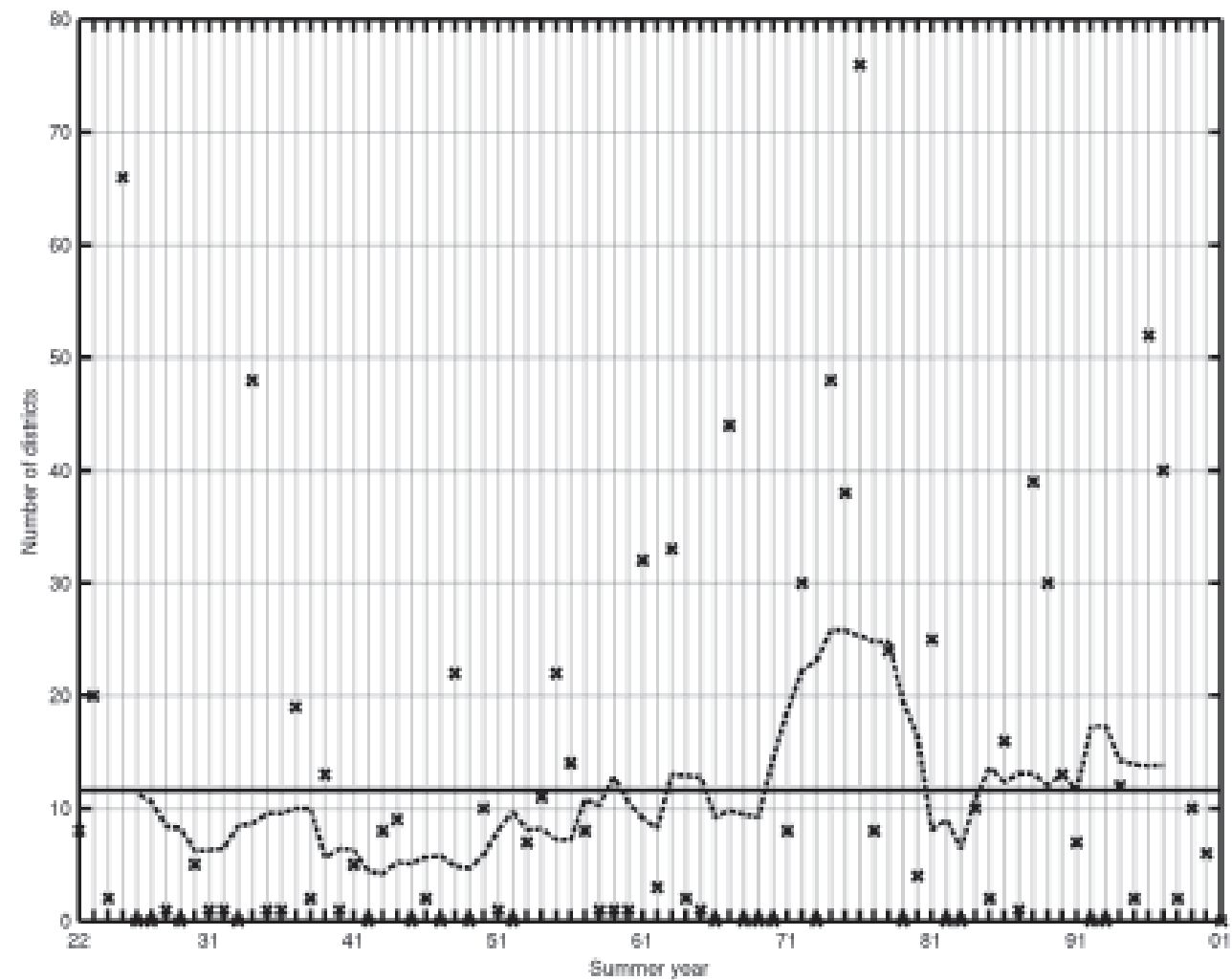

Figure 8

Number of wet districts (SPI 6-month > 1) for the 80 summer rainfall districts (Area 4 to 8) at the end of April with 9-year window running mean (dashed line) and 1922-2001 mean number of wet districts (solid line). 


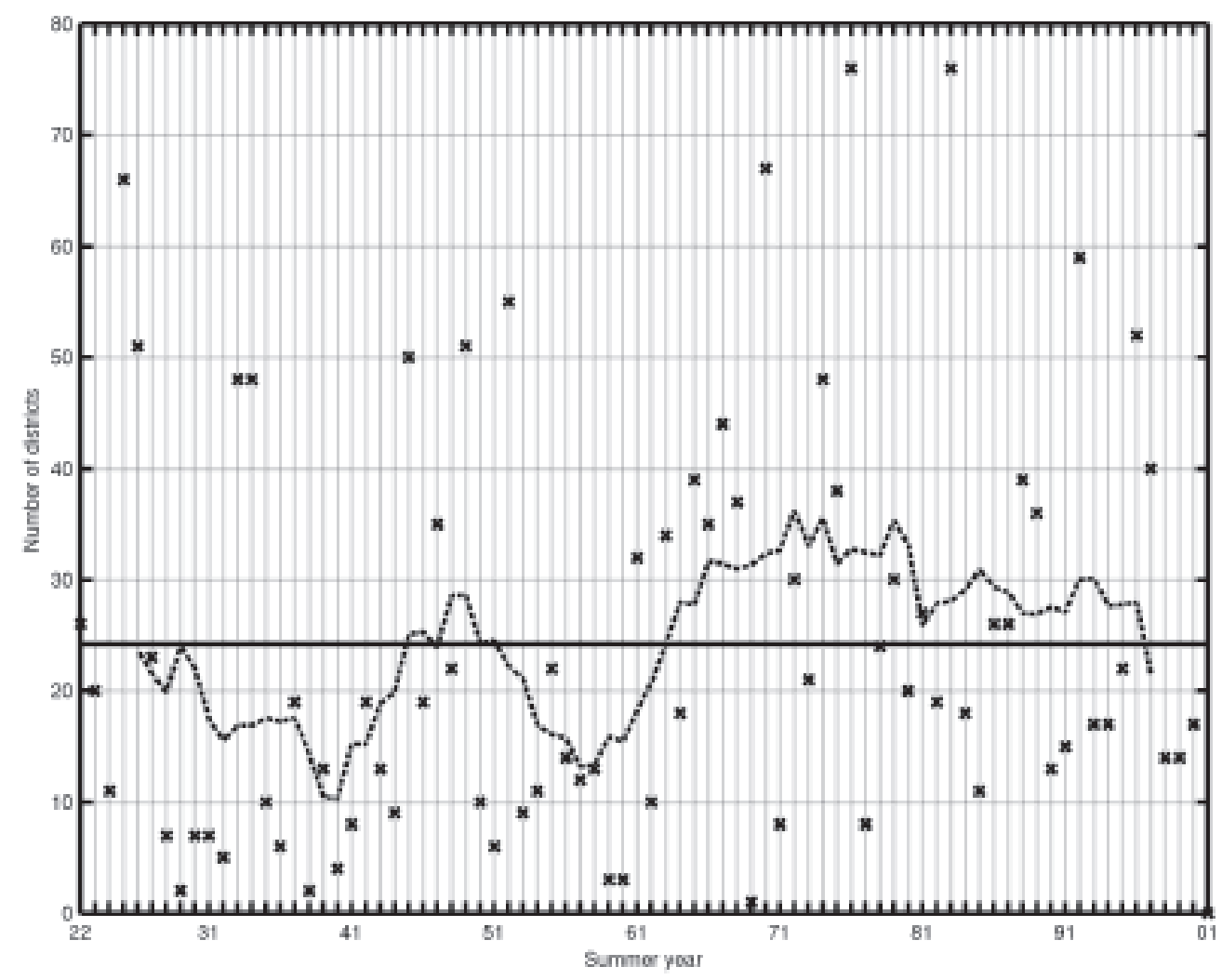

Figure 9

Total number of wet (SPI 6-month > 1) and dry districts (SPI 6-month <-1) for the 80 summer rainfall districts (Area 4 to 8) at the end of April with 9-year window running mean (dashed line) and 1922-2001 mean number of dry and wet districts (solid line).

ment of water resources. We look in this section at the number of dry or wet districts since 1922 for the summer rainfall area using the SPI 6-month at the end of April. Figure 7 shows the number of dry districts (SPI $<-1)$ per year for the 80 districts of summer rainfall (Area 4, 5, 6, 7 and 8) from 1922 to 2001 with a 9-year window running mean that indicate the mean average of dry district per decade. The average number of dry districts is 13 . There is considerable decadal variability in the number of dry districts per decade. The 16-20 years cycle in total rainfall anomaly documented by Tyson et al (1975), Louw (1982) and Reason and Rouault (2002) is visible in Fig. 7. It seems to have become longer in the 1990s. The number of dry district per year has increased at the end of the century, the result being in line with a precedent study (Richard et al., 2001). If we consider years with more than 20 dry districts we can consider 1926, 1927, 1933, 1945, 1947, 1949 and 1952 as dry years prior to 1962. Incidentally, 1926, 1933 and 1952 were El Niño years (Trenberth, 1997; Compagnucci et al., 2002). El Niño is usually linked to drought in South Africa (Van Heerden et al., 1988; Lindesay and Vogel, 1990). Since 1962, we had 10 dry years with an average of 44 dry districts. Seven of those years are El Niño years (1966, 1970, 1973, 1979, 1983, 1987, 1992 and 1995).This is consistent with the work of Richard et al. (2000).

Figure 8 plots the number of wet districts per year (SPI $>1)$ with a 9-year window running mean. On average there are 12 wet districts per year. The 16-20 years cycle is not seen in the number of wet districts per decade. There is an increase in the number of years experiencing a large number of wet districts. This confirms the work done by Mason et al. (1999), Alexander (1995) and Dai and Trenberth (1998). Indeed before 1962, 6 years $(1923,1925,1934$, 1948, 1955 and 1961) had more than 20 wet districts (SPI $>1$ ). 1925 and 1955 were La Niña year(Compagnucci et al., 2002). After 1962, years with more than 20 wet districts increased twofold (1963,
1967, 1972, 1974, 1975, 1976, 1978, 1981, 1988, 1989, 1996 and 1997). 1974, 1975, 1976, 1989 and 1996 were La Niña years according to Trenberth (1997) and Compagnucci et al. (2002). The definition of El Niño and La Niña years is not trivial and the evolution of El Niño has varied throughout the century (Trenberth and Stepaniak; 2002).

To summarise, Fig. 9 displays the total number of wet and dry districts per years for the 6-month SPI at the end of April and a 9-year window running mean. There are more dry or wet districts per decade since 1970. Dai and Trenberth (1998) have observed such an increase world-wide as well as in Southern Africa. They consider this increase in the global variation of wet and dry spells to be due to global warming and the increase in El Niño events since 1970. Their hypothesis is that the increased combined percentage areas experiencing dry or wet seasons is due to an increased hydrological cycle caused by increased greenhouse gases. Extreme events increase (floods and droughts) but the mean remains the same. Whether the increase shown in Fig. 9 is part of a natural cycle (Tyson et al.; 2002) or due to global warming (Dai and Trenberth, 1998) must be studied more deeply.

\section{Conclusion}

Due to the complexity of rainfall regime in South Africa, it is difficult to monitor drought in real time with a chart showing percentage from normal or anomaly in total rainfall. Drought occurs often in South Africa in all climatic areas at all times of the year with different intensity, spatial extension and duration. Agricultural drought (3 to 6-month time scales) and hydrological droughts (1 to 2-year scale) are often decoupled. Each drought has a different signature. The SPI is a simple index based on rainfall only that can measure drought at different time scales with spatial homogeneity. The SPI can also be 
used to monitor excess moisture during a wet season that can aggravate consequences of floods. This may indicate a saturated catchment conducive to flood development if rainfall continues. It was recently used in many parts of the world (see introduction) but never in South Africa. This first application has permitted to observe some spatial characteristics of the droughts. Furthermore, their temporal distribution is particular with:

- The two strongest droughts have happened during the last two decades (1983 and 1992).

- Drought since the late 1960 are more often associated with El Niño events.

- There is considerable decadal variability in the spatial extension and intensity of droughts.

- Wet years are enhanced since the 1970s.

\section{Acknowledgements}

Funding for this study from the Water Research Commission, the National Research Foundation, the Centre National de Recherche Scientifique and the South Africa/France co-operation program is gratefully acknowledged. The SAWS generously supplied data analysed in this study. M Hayes provided the Fortran program used to calculate the SPI and gave us a great assistance.

\section{References}

ALEXANDER WJR (1995) Floods, droughts and climate change. $S$ Afr. J. Sci. 91 403-408.

ANCTIL F, LAROUCHE W and VIAU AA (2002) Exploration of the standardized precipitation index with regional analysis. Can. J. Soil Sci. 82 (1) 115-125.

COMPAGNUCCI RH, AGOSTA EA and VARGAS WM (2002) Climatic change and quasi-oscillations in central-west Argentina summer precipitation: Main features and coherent behaviour with southern African region. Climate Dyn. 18 (5) 421-435.

DAI A and TRENBERTH KE (1998) Global variation in droughts and wet spells: 1900-1995. Geophys. Res. Let. 25 3367-3370.

DOMONKOS P (2003) Recent precipitation trends in Hungary in the context of larger scale climatic changes. Natl. Hazards 29 (2) 255271

FARRAR TJ, NICHOLSON SE and LARE AR (1994) The influence of soil type on the relationships between NDVI, rainfall and soil moisture in semiarid Botswana. II. NDVI response to soil moisture. Remote Sensing of Environ. 50 121-133.

GUTTMAN NB (1998) Comparing the Palmer Drought Index and the Standardized Precipitation Index. J. Am. Water Resour. Assoc. 34 113-121.

GUTTMAN NB (1999) Accepting the Standardized Precipitation. $J$. Am. Water Resour. Assoc. 35 311-322.

HARSCH E (1992) Drought devastates Southern Africa. Drought Network News 4 (2) 17-19.

HAYES MJ, SVOBODA MD, WILHITE DA and VANYARKHO OV (1999) Monitoring the 1996 drought using the Standardized Precipitation Index. BAMS 80 429-438.

LLOYD-HUGHES B and SAUNDERS MA (2002) A drought climatology for Europe. Int. J. Clim. 22 (13) 1571-1592.

KEYANTASH J and DRACUP JA (2002) The quantification of drought: An evaluation of drought indices. BAMS 83 1167-1180.

KOMUSCU AU (1999) Using the SPI to analyze spatial and temporal pattern of drought in Turkey. Drought Network News 11 7-13.

LANA X, SERRA C and BURGUENO A (2002) Patterns of monthly rainfall shortage and excess in terms of the standardized precipitation index for Catalonia (NE Spain). Int. J. Clim. 21 (13) 16691691.
LINDESAY JA and VOGEL CH (1990) Historical evidence for Southern Oscillation-southern African rainfall relationships. Int. J. Clim. 10 679-689.

LOUW WJ (1982) Oscillations in Orange free State Rainfall. Technical paper (South Africa Weather Bureau) no. 11, Weather Bureau, Dept. of Transport. $52 \mathrm{pp}$.

LOS SO, JUSTICE CO and TUCKER CJ (1994) A global $1^{\circ}$ by $1^{\circ} \mathrm{NDVI}$ data set for climate studies derived from the GIMMS continental NDVI data. Int. J. Remote Sensing 15 3519-3546.

MASON SJ, WAYLEN PR, MIMMACK GM, RAJARATNAM B and HARRISON MJ (1999) Changes in extreme rainfall events in South Africa. Climatic Change 41 249-257.

McKEE TB, NJ DOESKEN and J KLEIST (1993) The relationship of drought frequency and duration to time scales. Pre-prints, 8th Conf. on Appl. Climat., 17-22 January, Anaheim, CA. 179-184.

McKEE TB, DOESKEN NJ and KLEIST J (1995) Drought monitoring with multiple time scales. Pre-prints, 9th Conf. on Appl. Clim., Dallas, TX. 233-236.

MEIGH JR, McKENZIE AA and SENE KJ (1999) A grid-based approach to water scarcity estimates for Eastern and Southern Africa. Water Resour. Manage. 13 85-115.

MIN SK, KWON WT, PARK EH and CHOI Y (2003) Spatial and temporal comparisons of droughts over Korea with East Asia. Int. J. Clim. 23 (2) 223-233.

PALMER WC (1965) Meteorological drought. U.S. Department of Commerce. Weather Bureau Research Paper 45. 58 pp.

REASON CJC and ROUAULT M (2002) ENSO-like decadal variability and South African rainfall. Geophys. Res. Let. 29 (13) DOI :10.1029/ 2002 GL014663.

RICHARD Y and POCCARD I (1998) A statistical study of NDVI sensitivity to seasonal and interannual rainfall variations in Southern Africa. Int. J. Remote Sensing 19 2907-2920.

RICHARD Y, TRZASKA S, ROUCOU P and ROUAULT M (2000) Modification of the Southern African rainfall variability/El Niño Southern Oscillation relationship. Climate Dyn. 16 886-895.

RICHARD Y, FAUCHEREAU N, POCCARD I, ROUAULT M and TRZASKA S (2001) XXth Century Droughts in Southern Africa Spatial and temporal variability, teleconnections with oceanic and atmospheric conditions. Int. J. Clim. 21 873-885.

SOUTH AFRICAN WEATHER BUREAU (1972) District rainfall for South Africa and the annual march of rainfall over southern Africa. South African Weather Bureau, WB35, Pretoria.

SEILER RA, HAYES M and BRESSAN L (2002) Using the standardized precipitation index for flood risk monitoring. Int. J. Clim. 22 1365-1376.

SVOBODA M, LECOMTE D, HAYES M, HEIM R, GLEASON K, ANGEL J, RIPPEY B, TINKER R, PALECKI M, STOOKSBURY D, MISKUS D and STEPHENS S (2002) The Drought Monitor. BAMS 83 1181-1190.

TRENBERTH KE (1997) The Definition of El Niño. BAMS 78 27712777.

TRENBERTH KE and STEPANIAK DP (2002) Indices of El Niño Evolution. J. Clim. 14 1697-1701.

TYSON PD, DYER TGJ and MAMETSE MN (1975) Secular changes in South African rainfall: 1880 to 1972. Quarterly J. Royal Meteorol. Soc. 101 817-833.

TYSON PD, COOPER GRJ and McCARTHY TS (2002) Millenial to multi-decadal variability in the Climate of Southern Africa. Int. $J$. Clim. 22 1105-117. DOI:10.1002/joc.787.

VAN HEERDEN J, TERBLANCHE DE and SCHULZE GC (1988) The Southern Oscillation and South African summer rainfall. J. Climatol. 8 577-597.

VAN ROOY MP (1980) Extreme Rainfall Anomalies Over Extensive Parts of South Africa During Period of 1 to 5 Successive Summer Years. Technical paper (South Africa Weather Bureau) no. 8, Weather Bureau, Dept. of Transport. $32 \mathrm{p}$.

WU H, HAYES MJ, WEISS A and HU Q (2001) An evaluation of the Standardized Precipitation Index, the China-Z Index and the statistical Z-Score. Int. J. Clim. 21 (6) 745-758. 